\title{
Heterogeneous Hydrogenation Catalyses over Recyclable Pd(0) Nanoparticle Catalysts Stabilized by PAMAM-SBA-15 Organic-Inorganic Hybrid Composites
}

Yijun Jiang and Qiuming Gao*

State Key Laboratory of High Performance Ceramics and Superfine Microstructures, Shanghai Institute of Ceramics, Graduate School, Chinese Academy of Sciences, Shanghai 200050, People's Republic of China

\section{Procedure for preparing APTMS-Functionalized SBA-15}

SBA-15 was synthesized by the literature methods ${ }^{18}$. The as-prepared material was calcined at $550{ }^{\circ} \mathrm{C}$ for $6 \mathrm{~h}$. Prior to functionalization, the SBA-15 was dried at $120{ }^{\circ} \mathrm{C}$ for $24 \mathrm{~h}$. Excess 3-aminopropyltrimethoxysiliane ( $5 \mathrm{~mL}, 0.47 \mathrm{~g}$, APTMS) was added to $6 \mathrm{~g}$ of SBA-15 in anhydrous toluene. The mixture was allowed to stir for $24 \mathrm{~h}$ at room temperature under argon. The resulted solid was filtered, washed with toluene, and dried at room temperature overnight.

\section{Procedure for preparing Gn-PAMAM-SBA-15}

Amine-funcionalized SBA-15 $(6 \mathrm{~g})$ and methyl acylate $(20 \mathrm{~mL})$ in dry methanol $(100 \mathrm{~mL})$ were stirred at $25{ }^{\circ} \mathrm{C}$ for 3 days under argon. The suspension was cooled and filtered through a medium pore frit and washed with methanol $(100 \mathrm{~mL})$ for 3 times. The residual solvent removed in vacuum affording G0.5-PAMAM-SBA-15. The resulting powder was then added to ethylenediamine $(75 \mathrm{~mL})$ in dry methanol $(150 \mathrm{~mL})$ and stirred at $25{ }^{\circ} \mathrm{C}$ for $3 \mathrm{~d}$ under argon. The resulting first generation G1-PAMAM-SBA-15 was isolated by filtration and washed with methanol $(3 \mathrm{X} 100 \mathrm{~mL})$. The residual solvent was removed in vacuum. The second, third, and fourth generation dendrimers ${ }^{\#}$ were prepared in a similar process by repeating the required steps except the reaction was kept at $45{ }^{\circ} \mathrm{C}$ for $5 \mathrm{~d}$.

\section{Procedure for preparing Pd(0)-Gn-PAMAM-SBA-15}

In a typical experiment, $0.2 \mathrm{~g}$ Gn-PAMAM-SBA-15 powder was added to $20 \mathrm{~mL}$ of $10^{-2} \mathrm{M}$ $\left(\mathrm{NH}_{4}\right)_{2} \mathrm{PdCl}_{4}$ aqueous solution and stirred for $12 \mathrm{~h}$ at room temperature. The mixture was then centrifugated and washed 3 times with $50 \mathrm{~mL}$ water under ultrasonic for one minute. At last, a yellow powder was obtained. The resulting yellow powder was dried at $60{ }^{\circ} \mathrm{C}$ in a dry-box. Consequently, the yellow powder was reduced by $20 \mathrm{~mL}$ of $0.1 \mathrm{M} \mathrm{NaBH}_{4}$ aqueous solution to get a dark brown mixture. The mixture was then centrifugated and washed 3 times with $50 \mathrm{~mL}$ water under ultrasonic for one minute. Finally, a dark brown powder (Pd(0)-Gn-PAMAM-SBA-15) was obtained.

\section{Hydrogenations}

Catalytic hydrogenations were run in a 100-mL, 3-neck, round-bottomed flask at room temperature (30 $\left.\pm 2{ }^{\circ} \mathrm{C}\right) . \mathrm{H}_{2}$ was bubbled through a glass pipe at the bottom of the solution at an invariable rate controlled by a valve, and the solution was stirred throughout the reaction at a constant agitation speed. A certain amount of allyl alcohol and $0.01 \mathrm{~g}$ of different generation catalysts were contained in the methanol-water solution $(50 \mathrm{~mL} 4: 1 \mathrm{~V} / \mathrm{V})$ initially. Suspensions of the catalysts in solution were bubbled with $\mathrm{H}_{2}$ for 30 min before adding the substrates. Gas chromatography (SP-6890 equipped with AT-SE-30 capillary column) was used to monitor the reactions. The sensitivity of the flame-ionization detector was assumed

\footnotetext{
\# More defects inevitably exist for the structures of the dendrimers compared with that of the theoretic ones due to the incomplete reactions during the synthetic processes (see Table S3). Thus, they are more accurate to be called hyperbranched polymers.
} 
to be the same for products and reactants because they contain the same number of carbon atoms. This assumption was verified to be so good that the error is less than $1 \%$ by testing the standard samples. In our system, the main byproduct is acetone identified by using a standard sample. Due to the high conversion $(>99.5 \%)$ of the reaction, the turnover frequencies (TOFs) of generations 1-4 catalysts were calculated from the formula, TOF $=$ substrate hydrogenated $(\mathrm{mol})$ versus the time $(\mathrm{h})$, when the reaction reached the final and the catalyst employed (mol of $\mathrm{Pd}$ ). To study the dependencies of initial reaction rates $\left(r_{0}\right)$ on initial concentrations $\left(C_{0}\right)$ of allyl alcohol over the generations 2 and 3 catalysts, the initial reaction rates were calculated from the last points of the linear portions of plots. TOFs were also calculated from the slopes of the linear forcing the intercept to be zero except in the case of the hydrogenations of $1 \mathrm{mmol}$ and $2 \mathrm{mmol}$ allyl alcohol over the generation 3 catalyst. In that case, the intercept was not forced to be zero because of a small offset. Fitting the intercept rather than forcing the fit through zero resulted in only small $(<15 \%)$ decrease in the turn over frequency. The values of TOFs calculated from the two methods resulted in only small $(<10 \%)$ changes.

\section{Determination of the amount of $\operatorname{Pd}(0)$ in the catalysts}

To evaluate the catalyst performance quantitatively, the amounts of $\operatorname{Pd}(0)$ in the catalysts must be known. All the catalysts (generation 1-4) were determined by inductively coupled plasma optical emission spectroscopy (ICP-AES, Vista Axial CCD Simultaneous) (Tab. S1). The amounts of Pd(0) in generations 1 and 2 catalysts $(9.23 \%, 9.24 \%)$ are a little higher than that in generations 3 and 4 ones $(7.62 \%, 8.77 \%)$ due to the decreases of the surface areas. 
Table S1. The amounts of $\operatorname{Pd}(0)$ in the catalysts of $\operatorname{Pd}(0)-G n-P A M A M-S B A-15(n=1-4)$

\begin{tabular}{c|cccc}
\hline Catalysts & $\begin{array}{c}\text { Pd(0)-G1-PAMAM } \\
\text {-SBA-15 }\end{array}$ & $\begin{array}{c}\text { Pd(0)-G2-PAMAM } \\
\text {-SBA-15 }\end{array}$ & $\begin{array}{c}\text { Pd(0)-G3-PAMAM } \\
\text {-SBA-15 }\end{array}$ & $\begin{array}{c}\text { Pd(0)-G4-PAMAM } \\
\text {-SBA-15 }\end{array}$ \\
\hline $\begin{array}{c}\text { Amounts of } \\
\text { Pd (wt.\%) }\end{array}$ & 9.23 & 9.24 & 7.62 & 8.77 \\
\hline
\end{tabular}

Table S2. The data of surface areas $\left(\mathrm{S}_{\mathrm{BET}}\right)$, pore volumes $(\mathrm{V})$ and pore sizes $\left(\mathrm{D}_{\mathrm{BJH}}\right)$ based on nitrogen adsorption experiments at $77 \mathrm{~K}$.

\begin{tabular}{llll}
\hline Generation & $\mathrm{S}_{\mathrm{BET}}\left(\mathrm{m}^{2} / \mathrm{g}\right)$ & $\mathrm{D}_{\mathrm{BJH}}(\mathrm{nm})$ & $\mathrm{V}\left(\mathrm{cm}^{3} / \mathrm{g}\right)$ \\
\hline $\mathrm{G}(0)$ & 320 & 7.4 & 0.61 \\
$\mathrm{G}(0.5)$ & 284 & 6.2 & 0.50 \\
$\mathrm{G}(1)$ & 240 & 6.2 & 0.44 \\
$\mathrm{G}(1.5)$ & 185 & 5.3 & 0.32 \\
$\mathrm{G}(2)$ & 94 & 5.3 & 0.17 \\
$\mathrm{Pd}(0)-\mathrm{G}(2)$ & 80 & 5.0 & 0.12 \\
$\mathrm{G}(2.5)$ & 16 & 4.3 & 0.05 \\
$\mathrm{G}(3)$ & 4 & $-{ }^{\mathrm{a}}$ & - \\
$\mathrm{G}(3.5)^{\mathrm{b}}$ & - & - & - \\
$\mathrm{G}(4)^{\mathrm{b}}$ & - & & - \\
\hline
\end{tabular}

${ }^{a}$ The data was not given due to the very low pore volume. ${ }^{b}$ The values of the $G(3.5)$ and G(4) were not given, because these samples did not adsorb any nitrogen, suggesting the pore of the SBA-15 was blocked by the dendrimers. The surface areas, pore volumes, and pore sizes decreased along with the increases of the generations, indicating that the dendrimers were constructed on the channel surfaces of the SBA-15. These phenomena agree well with the literature, ${ }^{17}$ in which dendrimers were grafted onto the channels of MCM-41. 
Table S3. Overall yields calculated from the experimental (TGA and elemental analyses (EA)) and theoretical weight losses.

\begin{tabular}{|c|c|c|c|c|c|c|c|}
\hline Generation & $\begin{array}{l}\mathrm{C} \\
\%\end{array}$ & $\begin{array}{l}\mathrm{H} \\
\%\end{array}$ & $\begin{array}{l}\mathrm{N} \\
\%\end{array}$ & $\begin{array}{c}\text { TGA } \\
\text { weight loss }^{\mathrm{a}} \\
\%\end{array}$ & $\begin{array}{c}\text { EA } \\
\text { weight loss } \\
\%\end{array}$ & $\begin{array}{c}\text { Theoretical } \\
\text { weight loss } \\
\%\end{array}$ & $\begin{array}{c}\text { Overall } \\
\text { yield } \\
\%\end{array}$ \\
\hline 0 & 8.42 & 1.30 & 2.79 & 10.71 & 11.36 & 11.04 & - \\
\hline 1 & 15.08 & 2.53 & 5.64 & 23.26 & 25.74 & 32.23 & 76.02 \\
\hline 2 & 20.30 & 3.08 & 7.80 & 36.06 & 36.16 & 60.54 & 59.65 \\
\hline 3 & 24.70 & 4.15 & 9.65 & 45.06 & 46.67 & 74.75 & 61.36 \\
\hline 4 & 28.06 & 4.40 & 11.16 & 52.50 & 50.96 & 86.19 & 60.02 \\
\hline
\end{tabular}

${ }^{\mathrm{a}}$ The weight losses corresponding to the supported dendrimers were determined by TGA between 120 and $1000{ }^{\circ} \mathrm{C}$, excluding the weight losses of the desorption water and further corrected by the weight loss of the unmodified SBA-15 support. ${ }^{b}$ The values of weight losses were obtained by EA and the amounts of oxygen calculated on the basis of the theoretical oxygen to carbon ratio of any given dendrimer. ${ }^{\mathrm{c}}$ The theoretical weight losses of the materials were calculated from the start material G0 assuming the formation of dendrimers at every step is complete. 

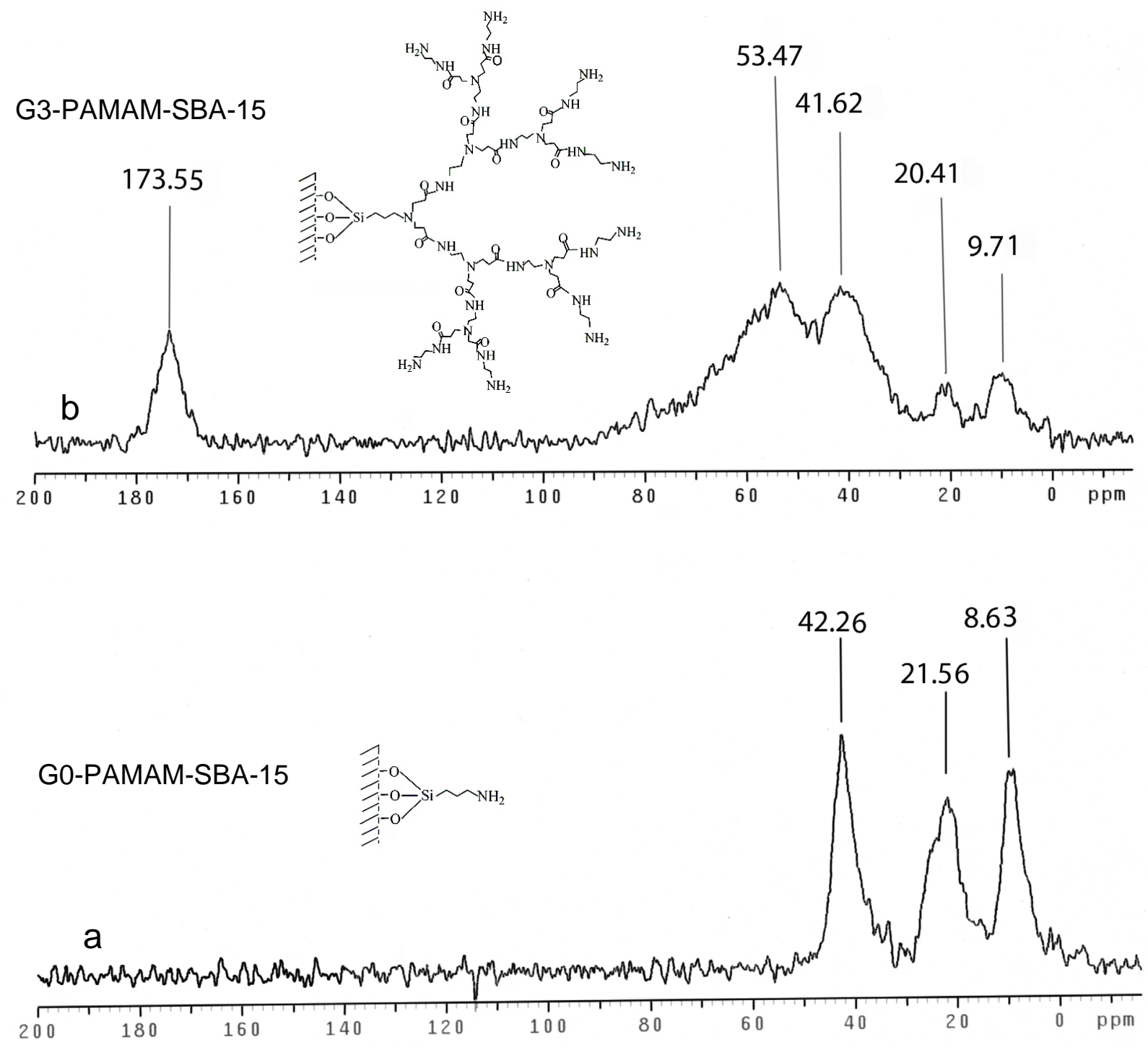

Figure S1. ${ }^{13}$ C CP MAS NMR spectra of G0-PAMAM-SBA-15 (a) and G3-PAMAM-SBA-15(b).

According to the literature ${ }^{17}$ three peaks at $8.63,21.56$ and $42.26 \mathrm{ppm}$ (a) are attributed to the three carbons between the $\mathrm{Si}$ and $\mathrm{N}$ atoms; the peaks at 9.71 and $20.41 \mathrm{ppm}$ (b) represent the two original aminopropylsilane species; the peak at $41.62 \mathrm{ppm}$ corresponds to the sum of the carbons of the methacrylate part of the dendrimers $\left(-\mathrm{CH}_{2} \mathrm{CH}_{2}-\mathrm{CONH}-\right)$ and the original aminoporpylsilane carbons; the peak at 53.47 is due to the carbons attached directly to the $\mathrm{N}$ atoms of the ethylenediamine species; and the broad peak at $173.55 \mathrm{ppm}$ is attributed to the sum of the carbonyl and amide carbons. 


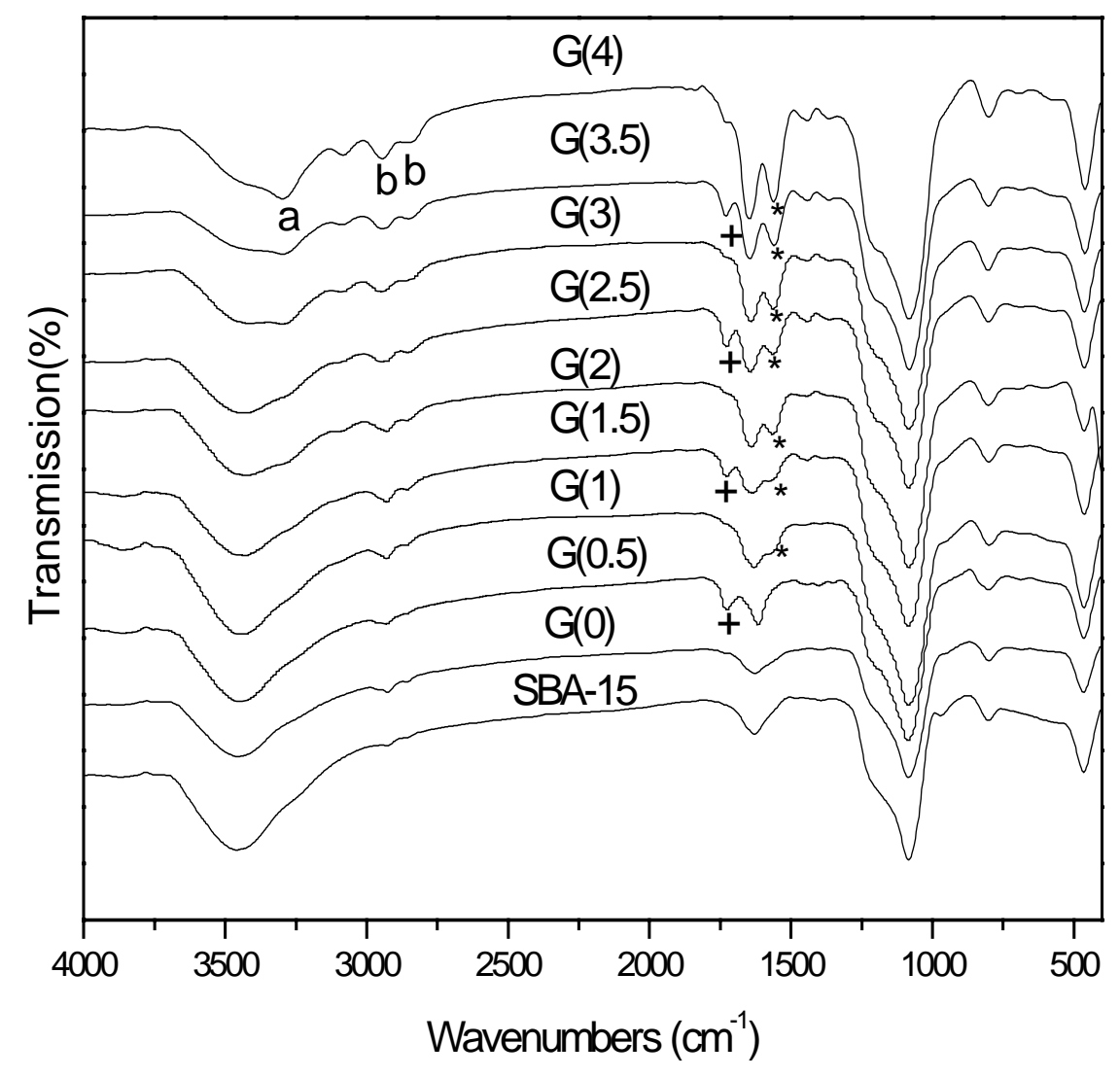

Figure S2. FT-IR spectra of the different generations of PAMAM-SBA-15 with (*) representing the N-H bending of the $-\mathrm{CONH}-$, , + ) $\mathrm{C}-\mathrm{O}$ the stretching of the ester groups, (a) $\mathrm{N}-\mathrm{H}$ stretching and (b) $\mathrm{C}-\mathrm{H}$ stretching, respectively. 

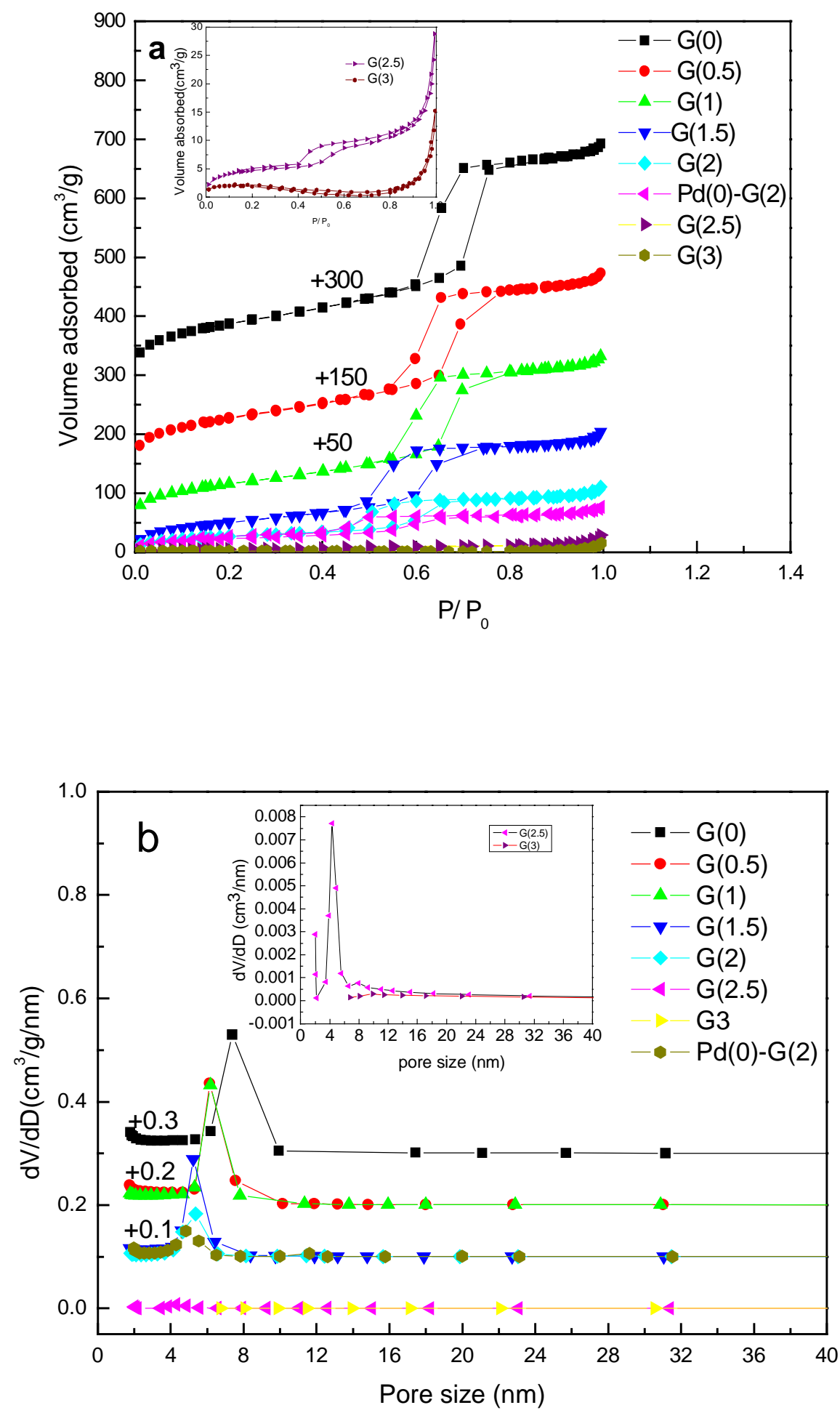

Figure S3. Nitrogen adsorption isotherms (a) and pore size distributions (b) of Gn-PAMAM-SBA-15 (n $=0-3)$. Inserts are the enlarged figures for generations 2.5 and $3 . P d(0)-G(2)$ refers to the catalyst Pd(0)-G2-PAMAM-SBA-15. 


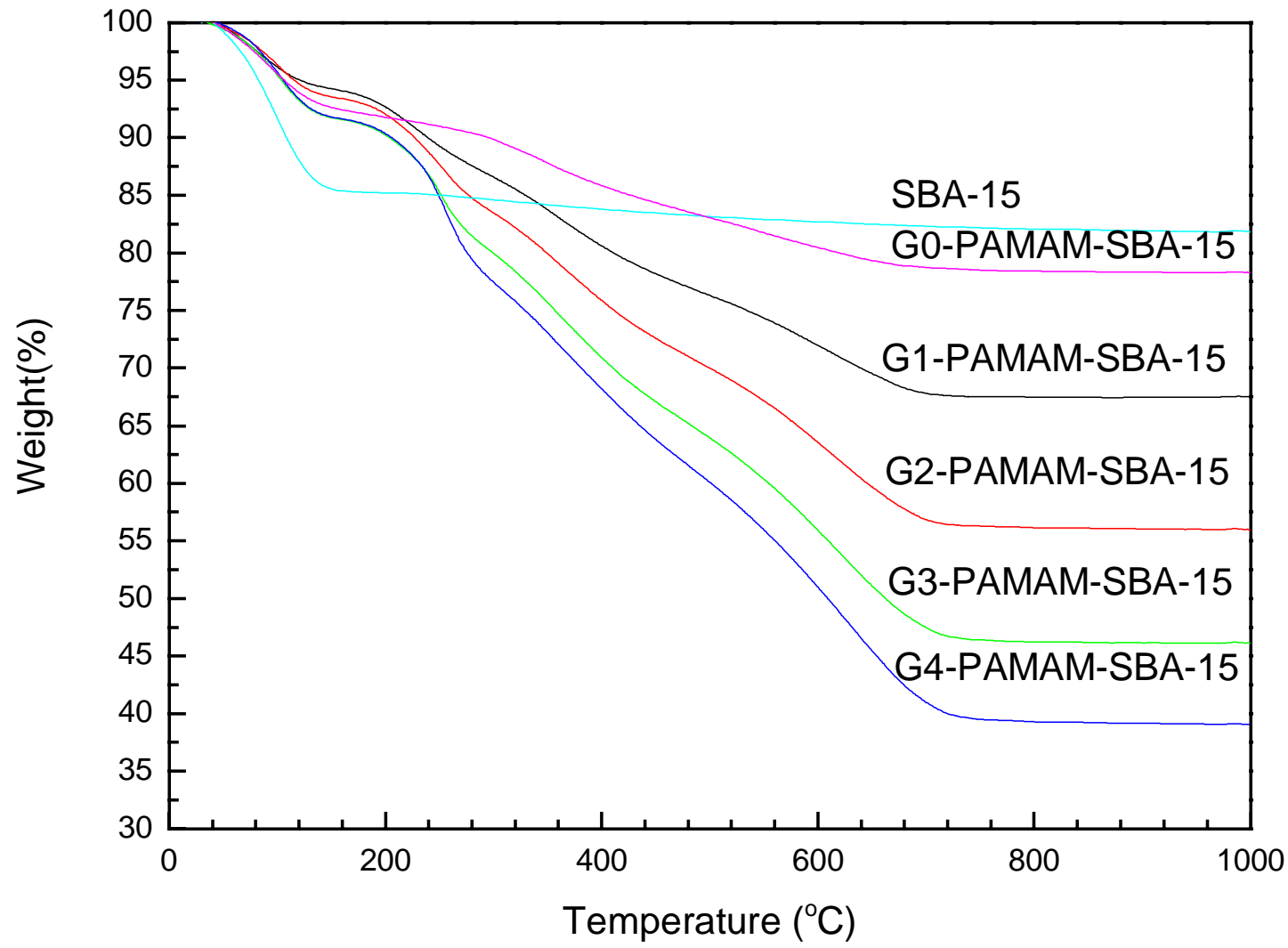

Figure S4. Weight losses measured by TGA for SBA-15 and Gn-PAMAM-SBA-15 ( $\mathrm{n}=0-4)$. 

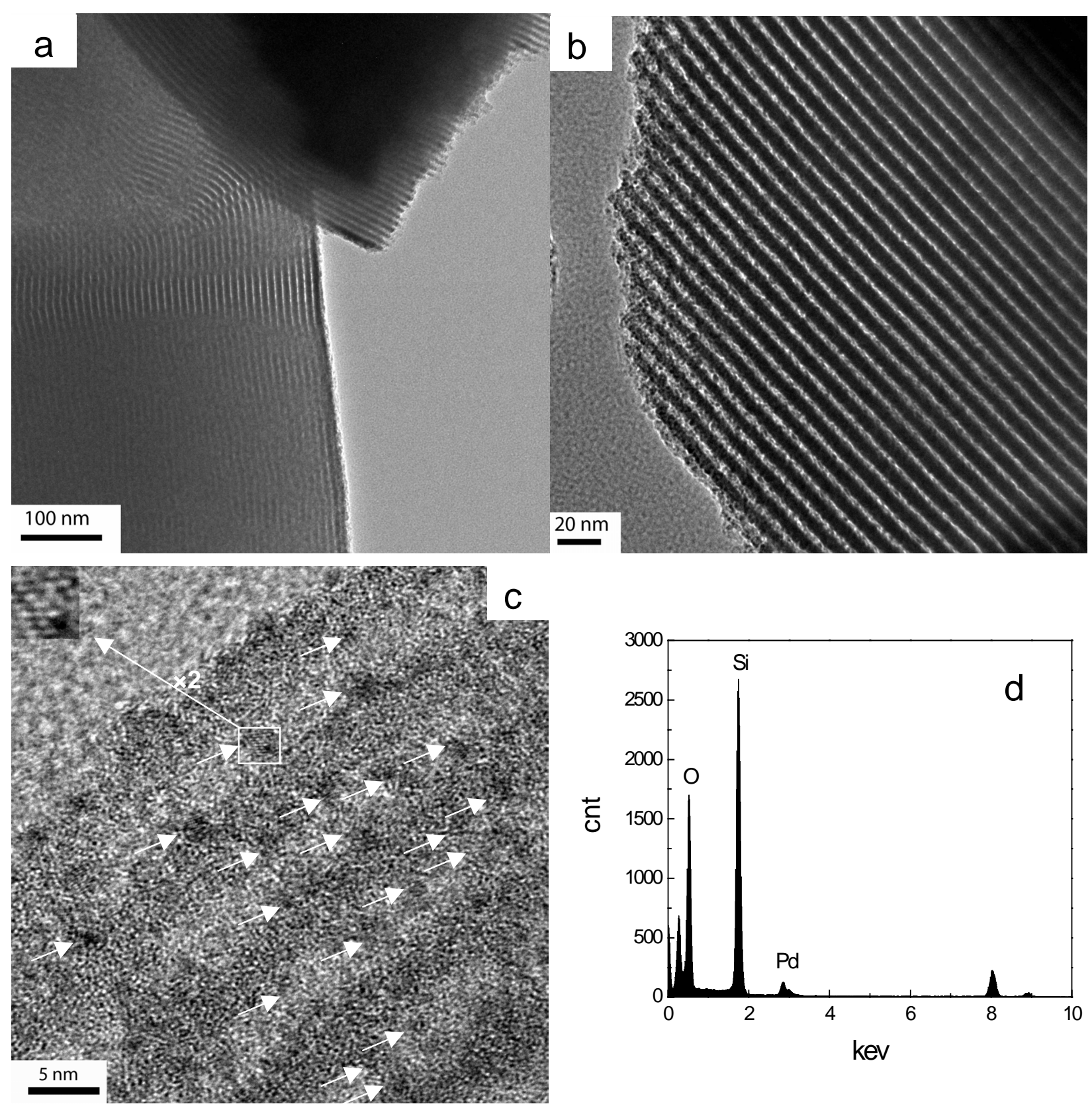

Figure S5. HRTEM of the G3-PAMAM-SBA-15 (a) and Pd(0)-G3-PAMAM-SBA-15 (b and c) catalysts and the EDS of Pd(0)-G3-PAMAM-SBA-15 sample (d). 


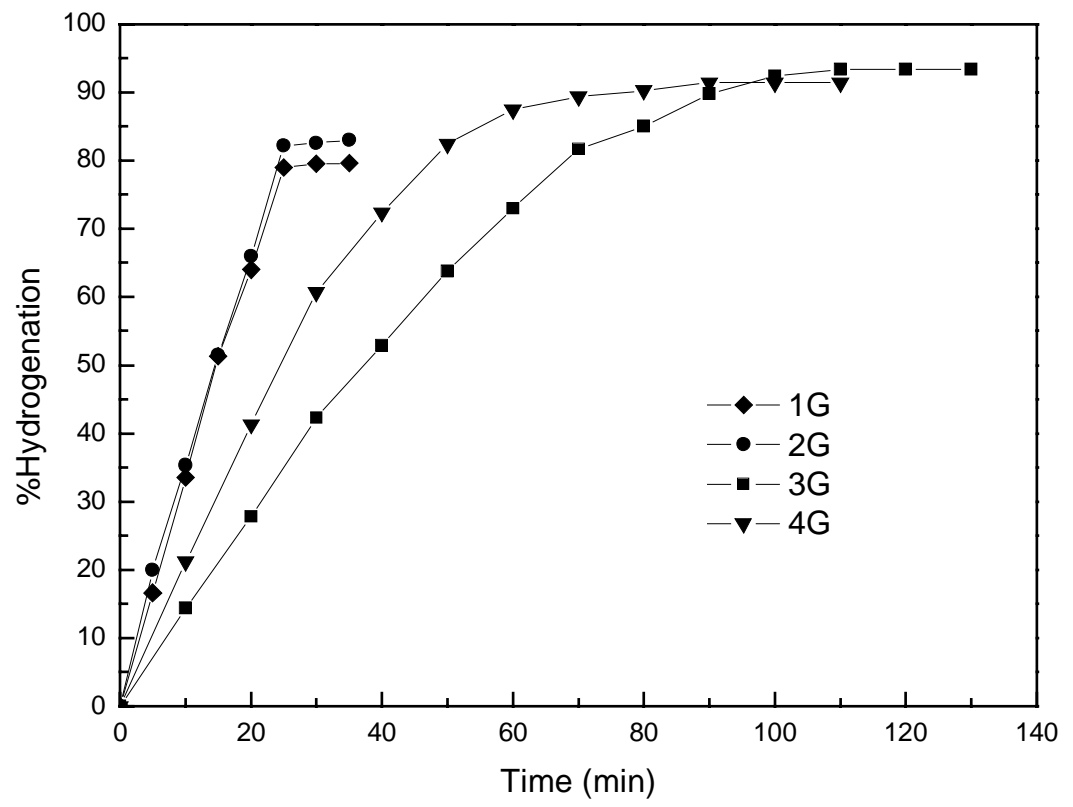

Figure S6. The percentage of the allyl alcohol hydrogenated vs reaction time over different generation (G1-G4) catalysts. Reaction conditions: allyl alcohol $(10 \mathrm{mmol})$, catalyst $(0.01 \mathrm{~g})$, and methanol- $\mathrm{H}_{2} \mathrm{O}(50$ $\mathrm{mL}, \mathrm{V} / \mathrm{V}=4 / 1)$. 


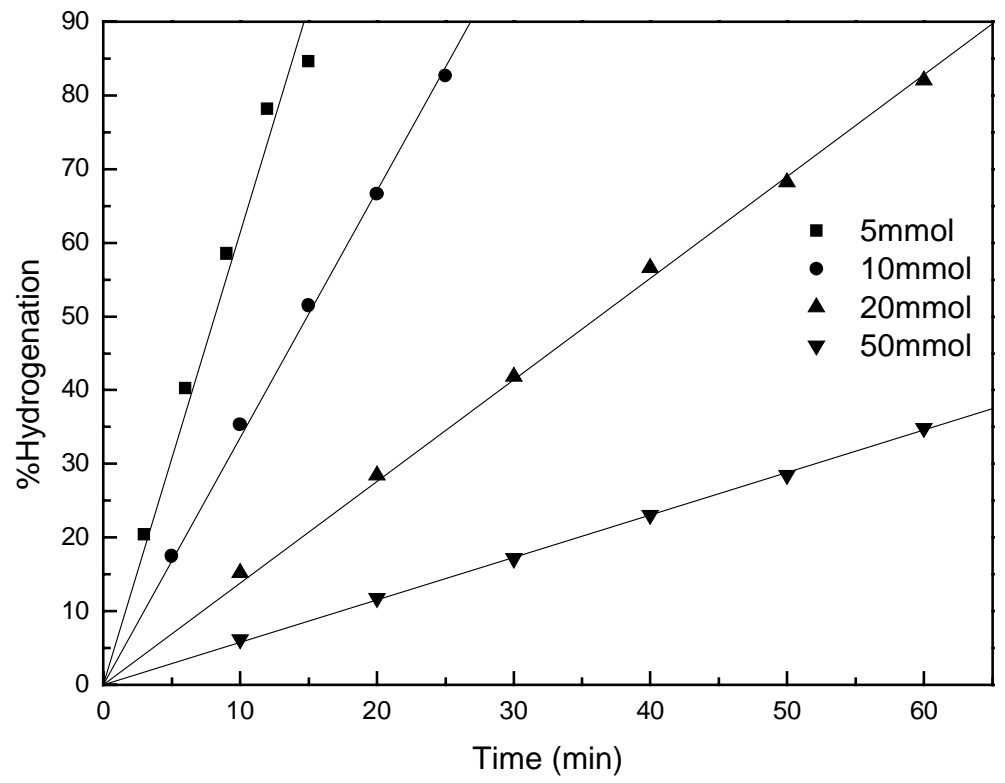

Figure S7. The percentage of the allyl alcohol hydrogenated vs reaction time for different concentration of substrate over generation 2 catalyst. Reaction conditions: allyl alcohols (5, 10, 20 and $50 \mathrm{mmol}$ ), generation 2 catalyst $(0.01 \mathrm{~g})$, and methanol- $\mathrm{H}_{2} \mathrm{O}(50 \mathrm{~mL}, \mathrm{~V} / \mathrm{V}=4 / 1)$. 


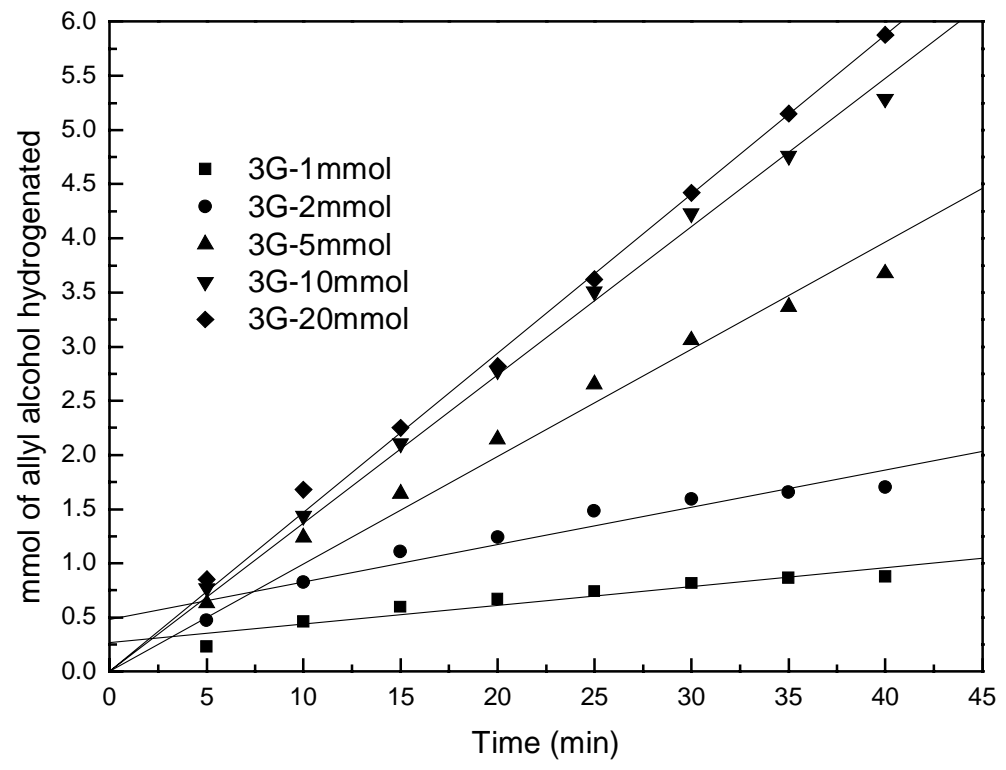

Figure S8. The amount of the allyl alcohol hydrogenated vs reaction time for $50 \mathrm{~mL}$ solutions initially containing 1, 2, 5, 10 and $20 \mathrm{mmol}$ of allyl alcohols. Reaction conditions: allyl alcohols (1, 2, 5, 10 and $20 \mathrm{mmol})$, generation 3 catalyst $(0.01 \mathrm{~g})$, and methanol- $\mathrm{H}_{2} \mathrm{O}(50 \mathrm{~mL}, \mathrm{~V} / \mathrm{V}=4 / 1)$. 


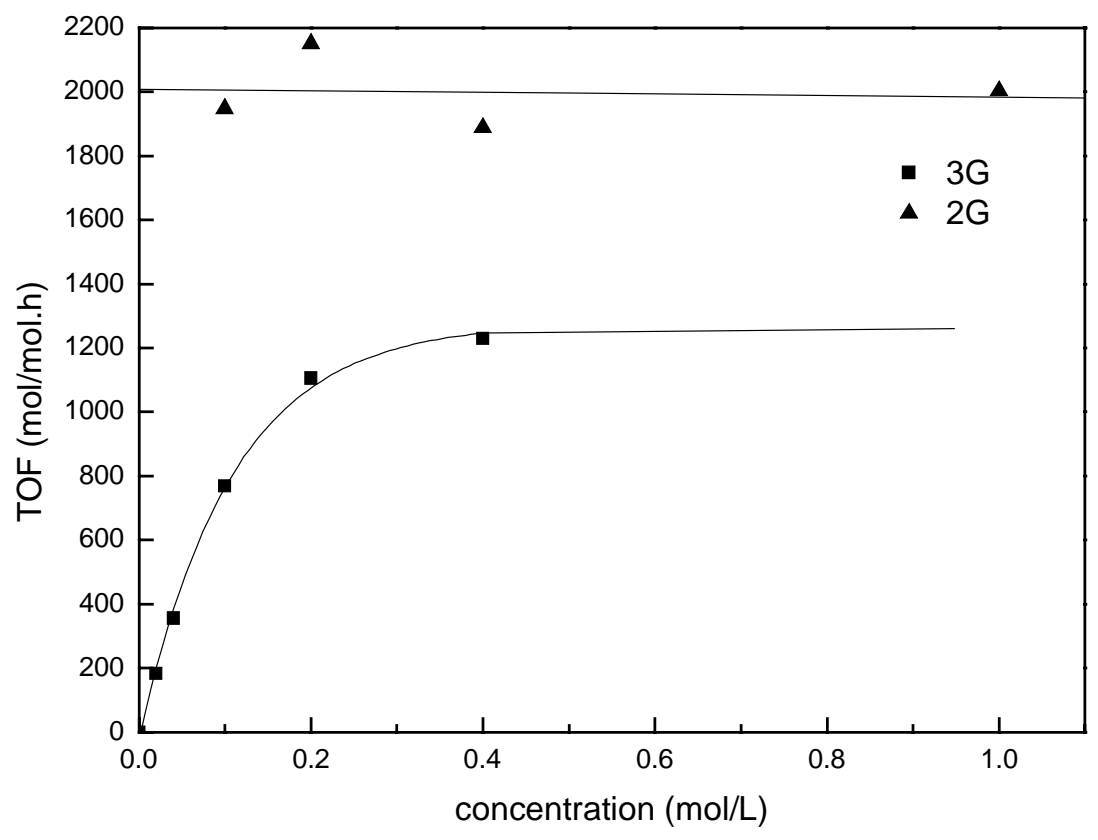

Figure S9. The hydrogenation rate is dependent of the initial allyl alcohol concentration over the generations 2 and 3 catalysts. The curve of generation 3 catalyst (squares) represents the fitted Langmuir-Hinshelwood model $\left(\mathrm{r}_{0}=\mathrm{kKC}_{0} /\left(1+\mathrm{KC}_{0}\right)\right)$ and that of generation 2 catalyst (triangles) represents the zero order reaction. 


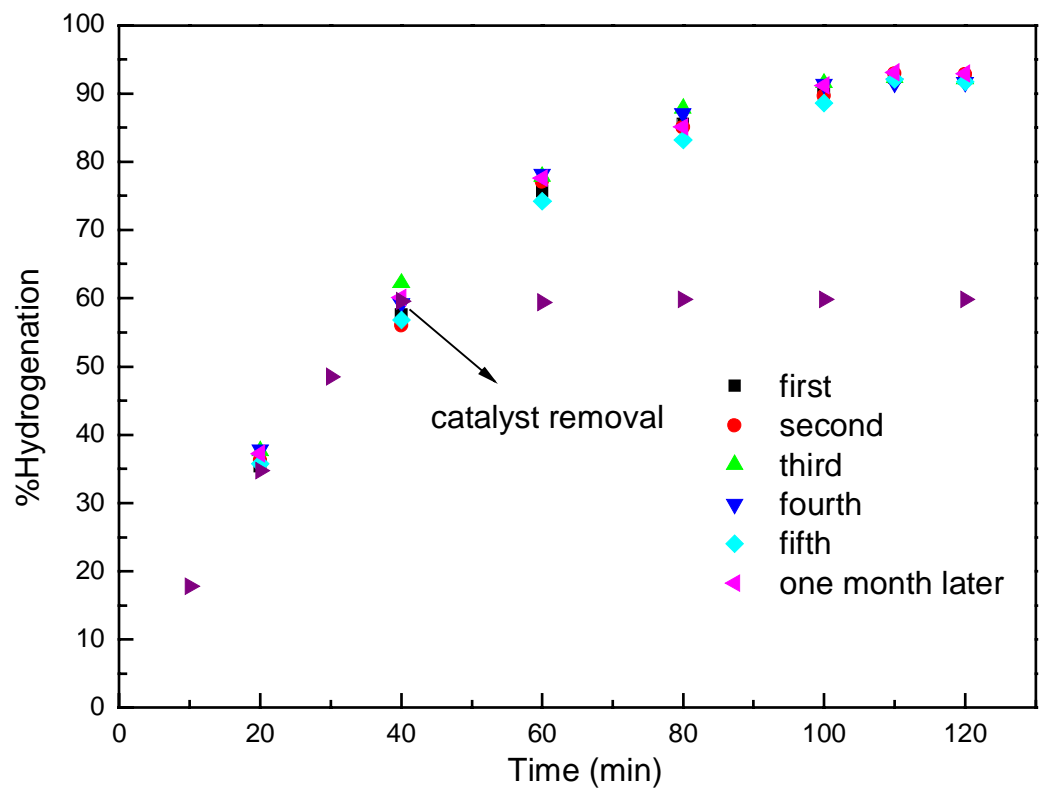

Figure S10. The effect of the removal of the catalyst of generation 3 and the hydrogenation over the catalysts, which were recycled for 5 times or stored under the ambient condition for one month. The arrow indicates the removal of catalyst of generation 3. Reaction conditions: allyl alcohol (10 mmol), catalyst of generation $3(0.01 \mathrm{~g})$, and methanol- $\mathrm{H}_{2} \mathrm{O}(50 \mathrm{~mL}, \mathrm{~V} / \mathrm{V}=4 / 1)$. 